\title{
Anophthalmia including next-generation sequencing-based approaches
}

\author{
Philippa Harding $\mathbb{D}^{1} \cdot$ Brian P. Brooks ${ }^{2}$ - David FitzPatrick ${ }^{3}$ Mariya Moosajee $\mathbb{B}^{1,4,5}$
}

Received: 18 February 2019 / Revised: 6 June 2019 / Accepted: 16 July 2019 / Published online: 29 July 2019

(c) European Society of Human Genetics 2019

\section{Disease characteristics}

\subsection{Name of the disease (synonyms)}

See Table 1, Column 1-“Name of disease" and Column 2 - "Alternative names".

\subsection{Online Mendelian Inheritance in Man (OMIM)\# of the disease}

See Table 1, Column 3-“OMIM\# of the disease".

\subsection{Name of the analysed genes or DNA/chromosome segments and OMIM\# of the gene(s)}

\subsubsection{Core genes (irrespective of being tested by Sanger sequencing or next-generation sequencing)}

See Table 1, Column 4-“Cytogenetic location", Column 5 - "Associated gene(s)" and Column 6-"OMIM\# of associated gene(s)".

Mariya Moosajee

m.moosajee@ucl.ac.uk

1 UCL Institute of Ophthalmology, London, UK

2 Ophthalmic Genetics \& Visual Function Branch, National Eye Institute, Bethesda, MD, USA

3 MRC Human Genetics Unit, University of Edinburgh, Edinburgh, UK

4 Moorfields Eye Hospital NHS Foundation Trust, London, UK

5 Great Ormond Street Hospital for Children NHS Foundation Trust, London, UK
1.3.2 Additional genes (if tested by next-generation sequencing, including whole exome/genome sequencing and panel sequencing)

See Table 2, Column 1-“Gene", Column 2-“Alternative names", Column 3-“OMIM\# of gene" and Column 4 - "Cytogenetic location".

\subsection{Mutational spectrum}

"True anophthalmia" is defined as abortion of eye development at the stage of the developing optic vesicle (3-4 weeks gestation) leading to absence of the eye, optic nerve and chiasm. However, more commonly "clinical anophthalmia" (often interchangeable with the term "severe microphthalmia", see Clinical Utility Gene Card for nonsyndromic microphthalmia [1]) occurs, where a small cystic remnant is detectable on pathology/imaging. Clinical anophthalmia is caused by the degeneration of the optic vesicle after it has formed, leading to the presence of a hypoplastic optic nerve, chiasm or tract. Anophthalmia is part of the phenotypic continuum with microphthalmia and coloboma, and can manifest bilaterally or unilaterally (with the contralateral eye exhibiting associated ocular anomalies [complex], such as ocular coloboma, microphthalmia, cataract and anterior segment dysgenesis) [2, 3]. In 33-95\% of anophthalmia and microphthalmia, associated systemic anomalies can be found, however, only $20-45 \%$ are the result of a known syndrome [2-4]. The most common extraocular features associated with anophthalmia/microphthalmia are craniofacial (including the face, ear and neck), limb and musculoskeletal anomalies [4-7].

A complex aetiology exists with chromosomal, monogenic and environmental causes identified. Chromosomal anomalies, including aneuploidy, triploidy, translocations, deletions and duplications account for $20-30 \%$ of anophthalmia/microphthalmia patients [2, 3, 8, 9]. Anophthalmia is clinically and genetically heterogeneous, and may be inherited through recessive (biallelic) or dominant modes, 


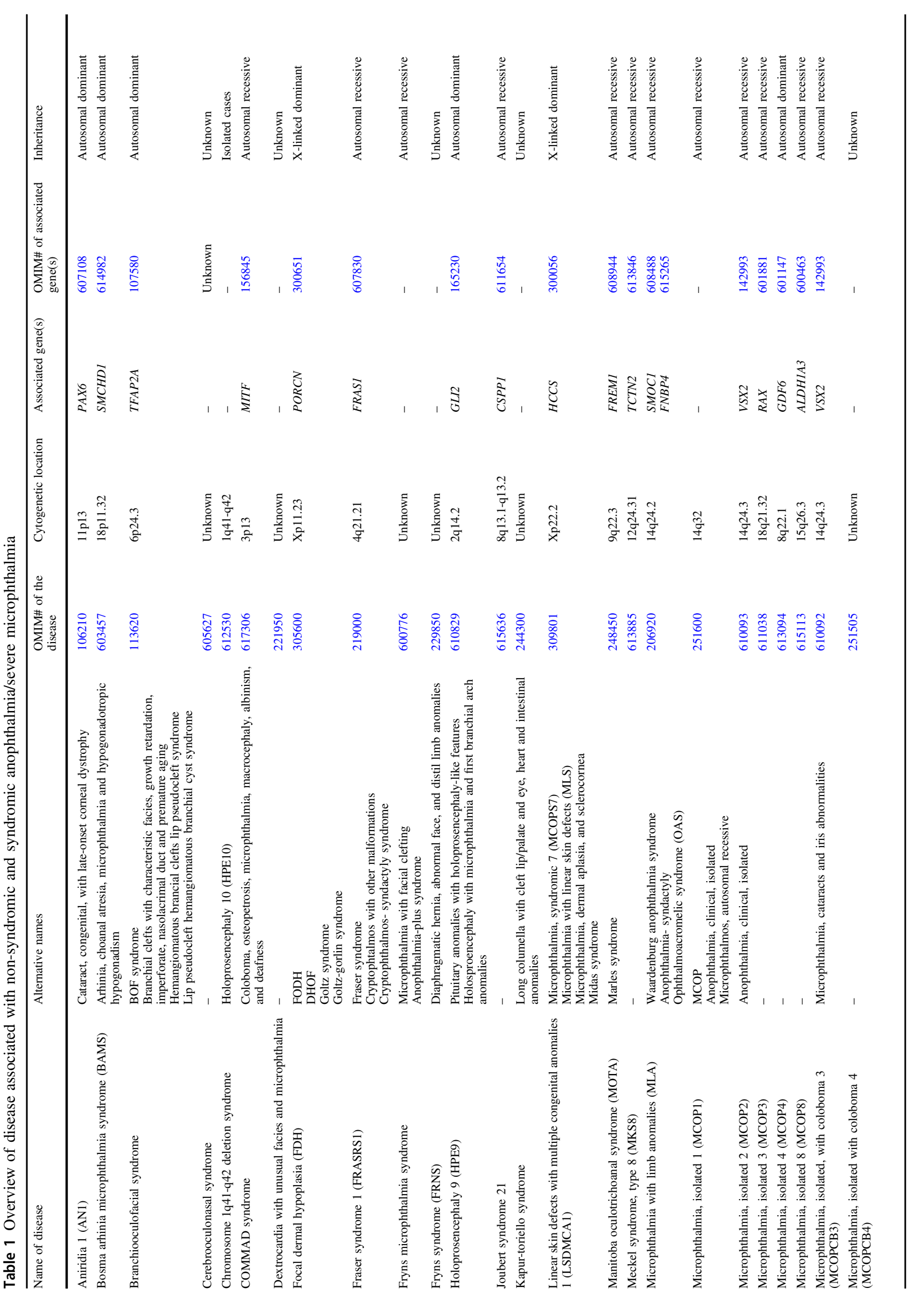




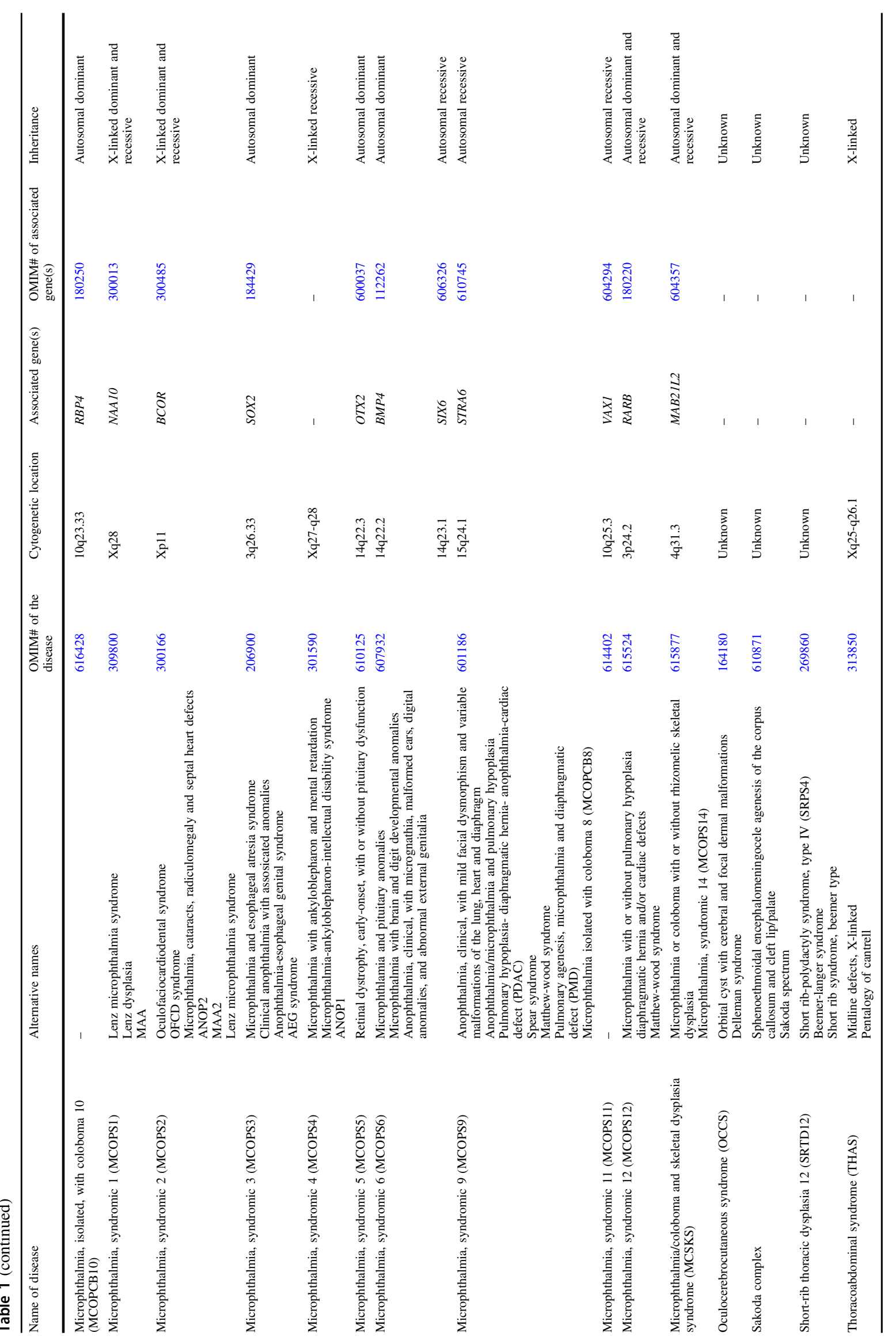


Table 2 Additional genes associated with anophthalmia/severe microphthalmia, tested by next-generation sequencing

\begin{tabular}{|c|c|c|c|}
\hline Gene & Alternative names & OMIM\# of gene & Cytogenetic location \\
\hline$B M P 7$ & - & 112267 & $20 \mathrm{q} 13.31$ \\
\hline$Y A P 1$ & - & 606608 & $11 \mathrm{q} 22.1$ \\
\hline$T B C 1 D 32$ & $\begin{array}{l}\text { C6orf170 } \\
\text { BROMI }\end{array}$ & 615867 & $6 q 22.31$ \\
\hline
\end{tabular}

although most cases of non-syndromic anophthalmia are sporadic and monoallelic resulting in haploinsufficiency, such as with PAX6 and SOX2. The occurrence of de novo changes, mosaicism and non-penetrance makes prediction of the inheritance pattern difficult. Diagnosis through molecular/genetic testing including next-generation sequencing and array comparative genomic hybridisation $(\mathrm{aCGH})$, can identify the genetic basis of bilateral anophthalmia or severe microphthalmia in $80 \%$ of cases, but this is considerably lower for unilateral cases $(<10 \%)[1,2,10]$. The low diagnostic frequency of unilateral anophthalmia/ severe microphthalmia indicates only a small number of disease-associated genes have been identified, which is not surprising given the complexity of eye development [9]. Advances in next-generation sequencing technology will allow for the identification of previously unknown deletions, duplications, inversions and translocations, as well as non-coding and splice variants [11]. Whole exome sequencing/whole genome sequencing (WES/WGS) screens all coding genes/the whole genome, which can increase the identification of novel disease-associated variants, including genes in associated loci where no candidate gene has yet been identified (Table 1), as well as eliminate loci which have been incorrectly associated with a disease [9, 12].

The major genes associated with anophthalmia broadly fall into two distinct categories (i) eye field initiating transcription factors, such as SOX2 (OMIM: 184429) and OTX2 (OMIM: 600037), or (ii) retinoic acid signalling pathway components, including STRA6 (OMIM: 610745), ALDH1A3 (OMIM: 600463) and RARB (OMIM: 180220) $[10,13,14]$.

Approximately $75 \%$ of incidences of bilateral anophthalmia or severe microphthalmia carry monoallelic (heterozygous) loss-of-function variants in $S O X 2$ or OTX2, or biallelic (homozygous or compound heterozygous) loss-of-function variants in STRA6 [10, 15]. A wide spectrum of variants have been implicated in anophthalmia, however, molecular analyses with larger patient cohorts from a range of different ethnic backgrounds is required to detect novel variants and more accurately estimate their relative contribution (Table 1, Table 2) [7, 10, 16-19].
The most common cause of bilateral anophthalmia and severe microphthalmia are heterozygous variants of $S O X 2$, with 76 known variants (63 of which are loss-of-function deletion, frameshift and nonsense) accounting for up to $40 \%$ of cases [4, 10, 15]. The most common SOX2 variant is the deletion (NM_003106.3) c.70_89del20 (p.Asn24Argfs*) [10]. The majority of variants $(60 \%)$ arise de novo, while $8 \%$ are known to be inherited [10]. Autosomal dominant inheritance of disease-associated SOX2 variants can be from an affected, non-penetrant or mosaic parent [4, 10, 20-22]. Haploinsufficiency of $S O X 2$ can cause isolated unilateral or bilateral anophthalmia, in addition to Syndromic Microphthalmia 3, where extraocular features include brain anomalies, neurocognitive delays, seizures, sensorineural hearing loss, oesophageal atresia, short stature, microcephaly and genital anomalies [4, 23].

Heterozygous variants in OTX2 are the second most prevalent cause of anophthalmia, with 47 known variant alleles, 38 of which are loss-of-function variants including indel, frameshift and nonsense [4, 10]. Approximately 40\% of OTX2 variants arise de novo and $35 \%$ are inherited $[10,15,24]$. The frequency of non-penetrance and variable expressivity is high with OTX2 changes [10, 15, 24-26]. There have also been multiple confirmed cases of gonadal mosaicism [10, 15, 24-26]. A recent study reported that for 69 microphthalmia, anophthalmia and coloboma (MAC) patients with an $O T X 2$ variant, in ten cases a heterozygous OTX2 variant was transmitted from an unaffected parent, compared with eight cases of inheritance from an affected parent [10]. In 2011, it was found that 2/3rds of reported parents carrying OTX2 mutations were unaffected due to mosaicism or non-penetrance [24]. The frequency of variable expressivity, non-penetrance and mosaicism for OTX2 variants may have implications for genetic counselling [25]. Patients with OTX2 associated anophthalmia/severe microphthalmia display extremely variable phenotypes, with complex ocular abnormalities including anterior segment dysgenesis, retinal dystrophy and hypoplasia or aplasia of the optic nerve and optic chiasm, and syndromic features including pituitary abnormalities, hypopituitarism, brain anomalies, seizures and developmental delay [4, 24, 27, 28].

Biallelic RAX loss-of-function variants account for 2-3\% of anophthalmia and microphthalmia, and include missense, nonsense, frameshift and splicing variants, as well as whole gene deletions [1, 10, 29-31]. Monoallelic carriers of $R A X$ variants display no ocular phenotype, while patients with biallelic changes are usually associated with bilateral severe microphthalmia, alongside neurological features such as intellectual deficiency and autism [10, 30, 31].

Monoallelic loss-of-function PAX6 changes account for $1-2 \%$ of MAC, and are commonly associated complex 
ocular features, including aniridia, although infrequently associated with systemic abnormalities [10]. Biallelic cases of $P A X 6$, such as compound heterozygous variants, usually result in termination of pregnancy or neonatal death [10].

Variants in STRA6 can contribute to bilateral anophthalmia, with 11 known missense and 15 loss-of-function [10]. STRA6 changes which alter function can cause both non-syndromic and syndromic anophthalmia, including Syndromic Microphthalmia 9 (OMIM: 601186), where termination of pregnancy or death is seen within the first 2 years of life [10, 32-34].

$A L D H 1 A 3$ variants have been estimated to occur in up to $10 \%$ of patients with bilateral anophthalmia and microphthalmia, with 11 identified disease-associated variants described [10, 35-37]. There has been a report of nonpenetrance, and although systemic abnormalities are rare, there is an association with behavioural problems such as autism [37, 38].

Monoallelic and biallelic $R A R B$ alleles can cause anophthalmia/microphthalmia due to a loss-of-function (such as (NM_000965.3) c.355C $>\mathrm{T} \quad$ (p.Arg119*) ) or gain-of-function (such as (NM_000965.3) c.1159C $>$ T (p.Arg387Cys)) [13, 14, 35]. Disease-associated RARB variants have been associated with Syndromic Microphthalmia 12, resulting in the termination of pregnancy, neonatal death, or severe developmental delay in those patients who survive the neonatal period $[13,14]$.

Only $1 \%$ of MAC cases screened for GDF6 found a disease-associated change, but variants are associated with bilateral anophthalmia or severe microphthalmia $[10,16]$. Variants of GDF6 are associated with Klippel Feil syndrome, where systemic features include congenital fusion of the cervical spine vertebrae, a low posterior hairline and a short neck with limited mobility [5].

All data were mined from primary literature or curated genomic and phenotype databases, including Online Mendelian Inheritance in Man, OMIM (http://omim.org/); ClinVar, public archive of interpretations of clinically relevant variants (http://www.ncbi.nlm.nih.gov/clinvar/); Gene Reviews (http://www.ncbi.nlm.nih.gov/books/NBK1116/) and OrphaNet (https://www.orpha.net/consor/cgi-bin/Disea se.php?lng=EN). Novel data should be shared through these databases. They were last accessed on 09 January 2019.

\subsection{Analytical validation}

Sequencing of both DNA strands. Disease-associated variants should be confirmed using genomic DNA from a new extraction. Disease-associated variants found with nextgeneration sequencing should be verified using Sanger sequencing or other specific molecular methods (e.g., PCR digest); for further details, see the Eurogentest Guideline [39]. It is important to look for segregation to determine whether the variant is de novo in isolated cases, providing a higher likelihood that it affects function. In clinical practice, aCGH or multiplex ligation-dependent probe amplification assay may be performed initially to detect deletions or duplications. Some molecular service labs also offer fluorescence in situ hybridisation to identify rearrangements or copy-number variation.

\subsection{Estimated frequency of the disease}

(Incidence at birth ("birth prevalence") or population prevalence. If known to be variable between ethnic groups, please report):

The reported birth prevalence of anophthalmia ranges from 0.18 to 0.6 per 10,000 , which is consistent across most countries [10, 17, 40-42]. In a prospective UK childhood incidence study of MAC cases (11.9 per $100,000)$, clinical anophthalmia was rare, being present in only $5.2 \%$ (7/135) of children under 16 [18]. Of the anophthalmic cases, two were bilateral, three were unilateral and two had microphthalmia or coloboma in the contralateral eye [8]. This study found significant ethnicity differences in the annual live birth incidence, however, these associations may be confounded by socioeconomic status [18]. There is no evidence of gender predilection.

Multiple births, maternal age over 40, low birthweight and low gestational age are associated risk factors for anophthalmia $[6,7,18,40]$. Furthermore, maternal smoking during early pregnancy, exposure to certain medications (including the antibiotic nitrofurantoin) during early pregnancy and maternal viral infections (including rubella, CMV and influenza) may increase the likelihood of having a child with anophthalmia [41, 43-47].

\subsection{Diagnostic setting}

\begin{tabular}{lll}
\hline & Yes. & No. \\
A. (Differential) diagnosis & $\bigotimes$ & $\square$ \\
B. Predictive testing & $\bigotimes$ & $\square$ \\
C. Risk assessment in relatives & $\bigotimes$ & $\square$ \\
D. Prenatal & $\bigotimes$ & $\square$ \\
\hline
\end{tabular}

Because of the time constraints of pregnancy, panel diagnostic or WES/WGS filtering is preferred if there is a request for prenatal diagnosis. 


\section{Test characteristics}

Genotype A: True positives C: False

or disease

negative

Present Absent B: False positives D: True negative

Test

\begin{tabular}{|c|c|c|c|}
\hline Pos. A & B & $\begin{array}{l}\text { Sensitivity } \\
\text { Specificity }\end{array}$ & $\begin{array}{l}\mathrm{A} /(\mathrm{A}+\mathrm{C}) \\
\mathrm{D} /(\mathrm{D}+\mathrm{B})\end{array}$ \\
\hline Neg. C & $\mathrm{D}$ & $\begin{array}{l}\text { Pos. predict value } \\
\text { Neg. predict } \\
\text { value }\end{array}$ & $\begin{array}{l}\mathrm{A} /(\mathrm{A}+\mathrm{B}) \\
\mathrm{D} /(\mathrm{C}+\mathrm{D})\end{array}$ \\
\hline
\end{tabular}

\subsection{Analytical sensitivity}

(Proportion of positive tests if the genotype is present in the analyte.)

\subsubsection{If tested by conventional Sanger sequencing}

Less than $100 \%$. The proportion is likely $<100 \%$, because primers may be localised on sequences containing SNVs or rare variants, which results in a preferential amplification of one allele (allele dropout). A supplementary deletion/ duplication diagnostic test should be performed for genes with a known proportion of large genomic deletions/duplications as outlined in the section "Analytical validation".

\subsubsection{If tested by next-generation sequencing}

Less than $100 \%$. The proportion is likely $<100 \%$, because there might be disease-associated variants in regions that could not be enriched and/or sequenced by next-generation sequencing owing to suboptimal coverage of some regions of interest with this technology depending on nextgeneration sequencing strategy. If amplicon-based enrichment strategies are being used, primers may be localised on SNVs or rare variants, which results in preferential amplification of one allele. In patients with a highly suggestive phenotype in whom testing for specific gene alterations proves negative, a supplementary deletion/duplication diagnostic test should be performed for genes with a known proportion of large genomic deletions/duplications as outlined in the section "Analytical validation".

\subsection{Analytical specificity}

(Proportion of negative tests if the genotype is not present.)

\subsubsection{If tested by conventional Sanger sequencing}

Nearly $100 \%$. False positives may arise owing to misinterpretation of rare polymorphic variants.

\subsubsection{If tested by next-generation sequencing}

Less than $100 \%$. The risk of false positives owing to misinterpretation of rare polymorphic variants may be higher compared with Sanger sequencing because of greater number of analysed genes.

\subsection{Clinical sensitivity}

(Proportion of positive tests if the disease is present.)

\subsubsection{If tested by conventional Sanger sequencing}

Of those patients that undergo genetic testing of known causative genes with Sanger sequencing, $<10 \%$ of patients with unilateral isolated anophthalmia will receive a molecular diagnosis. Those with bilateral severe cases will have a 75\% diagnostic rate if aCGH and the coding regions of the following four genes are screened; SOX2, OTX2, PAX6 and STRA6 [15].

\subsubsection{If tested by next-generation sequencing}

See section "If tested by conventional Sanger sequencing". Variant detection rates are higher when WES is combined with aCGH and high-resolution analysis of intragenic microdeletions and microduplications are performed. WGS may aid in the detection of functionaffecting variants in the promotor region, introns and other non-coding regulatory elements, and provide better coverage than exome sequencing. Regulatory element disruption in anophthalmia remains largely uncharacterised.

\subsection{Clinical specificity}

(Proportion of negative tests if the disease is not present.)

\subsubsection{If tested by conventional Sanger sequencing}

Unknown, however, if anophthalmia is not present, it is unlikely that a positive test will be detected.

\subsubsection{If tested by next-generation sequencing}

See section "If tested by conventional Sanger sequencing". 


\subsection{Positive clinical predictive value}

(Lifetime risk to develop the disease if the test is positive.) Anophthalmia is a congenital anomaly; hence, patients will be born with this defect, therefore nearly $100 \%$.

\subsection{Negative clinical predictive value}

(Probability not to develop the disease if the test is negative.)

Nearly $100 \%$ as a congenital anomaly (but need to check no evidence of microphthalmia through axial length measurements).

Index case in that family had been tested:

Nearly $100 \%$. If the non-affected relative is not a carrier of an identified disease-associated variant, they have no increased risk, except a small risk related to the prevalence in the general population.

Index case in that family had not been tested:

Unknown.

\section{Clinical utility}

\section{1 (Differential) diagnostics: the tested person is clinically affected}

(To be answered if in 1.9 "A" was marked)

\subsubsection{Can a diagnosis be made other than through a genetic test?}

\begin{tabular}{lll} 
No. & $\square($ Continue with 3.1.4) \\
Yes. & $\bigotimes$ & \\
& Clinically & $\square$ \\
& Imaging & $\square$ \\
& Endoscopy & $\square$ \\
& Biochemistry & $\square$ \\
& Electrophysiology & $\square$ \\
& Other (please describe) & \\
\hline
\end{tabular}

\subsubsection{Describe the burden of alternative diagnostic methods to the patient}

Prenatal diagnosis can be performed through $2 \mathrm{D}$ or $3 \mathrm{D}$ ultrasonography during the second trimester (or at 12 weeks post-conception with a transvaginal ultrasound) or foetal magnetic resonance imaging (MRI) to visualise the orbit [2, 48-50]. However, ultrasound examination may appear normal in affected foetuses, particularly in early scans where eye development is arrested after initial formation of the early eye cup [51].

Postnatal diagnosis can be made through clinical examination. In order to define whether anophthalmia is "true" or "clinical/severe microphthalmia", MRI brain and orbit imaging can be used to determine the absence of the globe, optic nerve and optic chiasm or amorphous tissue with a hypoplastic optic nerve, respectively [2, 52].

A diagnosis of anophthalmia can be made relatively easily and cost-effectively, but if this anomaly is seen, children should be investigated within a multidisciplinary team, including paediatricians and clinical geneticists, to ensure this is not part of a syndrome. Further monitoring may be required as syndromic manifestations may present later in childhood.

\subsubsection{How is the cost effectiveness of alternative diagnostic methods to be judged?}

Clinical examination and ultrasound imaging provides a cost-effective diagnosis [1].

3.1.4 Will disease management be influenced by the result of a genetic test?

No.

Yes. $\otimes$

Therapy (please -

describe)

Prognosis (please Yes, if a variant in a gene is describe) associated with a syndrome, it may lead to further investigations for systemic involvement to prevent morbidity and maximise function, e.g., patients with SOX2 anophthalmia syndrome suffer from a range of multisystem abnormalities including seizures and sensorineural deafness, hence early diagnosis will lead to prompt supportive treatment, having long term health economic benefits.

Management Anophthalmia should be managed (please describe) by specialists with expertise in this condition. Socket expansion using enlarging conformers can minimise facial deformity, which can be started very soon after birth. In 
Table (continued)

patients with anophthalmia, there is often an underdevelopment of the bony orbit, eyelid or fornices. Without intervention, the socket remains underdeveloped and prevents the ability for prosthesis later in life. In addition, in unilateral cases may lead to more pronounced facial asymmetry. The cosmetic deformity may result in psychological stress for the patient in the social environment. Introduction of socket expanders to add volume to the socket facilitates the progressive growth. In addition, supportive treatment for associated systemic abnormalities identified by genetic diagnosis must be monitored e.g., reversal of sleep pattern treated with melatonin supplements, growth assessment due to pituitary abnormalities, such as in the case of SIX6 variants [52]. Genetic counselling should be provided for the patient and family where appropriate, especially if the mode of inheritance can be identified [2].

\subsection{Predictive setting: the tested person is clinically unaffected but carries an increased risk based on family history}

(To be answered if in 1.9 "B" was marked.)

\subsubsection{Will the result of a genetic test influence lifestyle and prevention?}

If the test result is positive (please describe):

Anophthalmia is a congenital eye anomaly, therefore, if it is not clinically present at birth then this will not develop later in life. However, if an individual is clinically unaffected but a carrier, this information will inform family planning if the mode of inheritance can be identified.

If the test result is negative (please describe):

If the clinically unaffected person has a negative test result, no further follow-up is required. The result will inform family planning.
3.2.2 Which options in view of lifestyle and prevention does a person at-risk have if no genetic test has been done (please describe)?

A patient with anophthalmia has no vision in the affected eye. If there is bilateral involvement, in addition to other syndromic features, this may impact all aspects of lifestyle including schooling and future profession. Hence, a clinical diagnosis can help to provide support from an early age for both the patient and family, at home and at school, and guide career and work choices.

\subsection{Genetic risk assessment in family members of a diseased person}

(To be answered if in 1.9 "C" was marked.)

3.3.1 Does the result of a genetic test resolve the genetic situation in that family?

Yes, although there may be variable expressivity, nonpenetrance and germline mosaicism, which will complicate the advice that can be given.

3.3.2 Can a genetic test in the index patient save genetic or other tests in family members?

If a disease-associated change is identified in the index patient, family members can be tested, but ophthalmic examination is also helpful, for example to ascertain microphthalmia or other related ocular features on the phenotypic continuum. Test negative family members, who are clinically unaffected, do not need any further investigation or monitoring.

3.3.3 Does a positive genetic test result in the index patient enable a predictive test in a family member?

Yes, if the variant is known.

\subsection{Prenatal diagnosis}

(To be answered if in 1.9 "D" was marked.)

3.4.1 Does a positive genetic test result in the index patient enable a prenatal diagnosis?

Yes. Germline mosaicism and/or non-penetrance render the prediction of recurrence risk difficult in monogenic anophthalmic individuals; however, molecular genetic studies for known variants are possible on amniotic fluid foetal cells withdrawn after 14 weeks of gestation or on chronic villus sampling at 10-12 weeks gestation, and can facilitate the 
diagnosis of anophthalmia [1, 2, 51]. In addition, transvaginal ultrasonography enables the detection of anophthalmia from 12 weeks gestation, through 2D or 3D ultrasonography during the second trimester or using foetal MRI to visualise and analyse the orbit of a foetus [2, 48-50].

Non-invasive prenatal diagnosis of aneuploidies and some monogenic disorders can be achieved by molecular testing of cell-free foetal DNA (cffDNA) from maternal plasma [53-58]. While non-invasive prenatal diagnosis of anophthalmia is not currently available, the reduced risk of non-invasive, early screening (7-9 weeks), makes cffDNA a valuable emerging tool for diagnosis of genetic disorders, particularly for patients with known risk [53, 54].

\section{If applicable, further consequences of testing}

Please assume that the result of a genetic test has no immediate medical consequences. Is there any evidence that a genetic test is nevertheless useful for the patient or his/her relatives? (Please describe)

Identifying the genetic cause can aid in identifying additional syndromic features in addition to guiding genetic counselling by identifying the mode of inheritance. Preimplantation diagnosis may be an option for bilateral anophthalmia/severe microphthalmia.

Acknowledgements This work was supported by EuroGentest2 (Unit 2: "Genetic testing as part of health care"), a Coordination Action under FP7 (Grant Agreement Number 261469) and the European Society of Human Genetics. MM gratefully acknowledges the support of the Wellcome Trust, Moorfields Eye Charity and National Institute for Health Research (NIHR) Biomedical Research Centre based at Moorfields Eye Hospital NHS Foundation Trust and UCL Institute of Ophthalmology.

\section{Compliance with ethical standards}

Conflict of interest The authors declare that they have no conflict of interest.

Publisher's note: Springer Nature remains neutral with regard to jurisdictional claims in published maps and institutional affiliations.

\section{References}

1. Richardson R, Sowden J, Gerth-Kahlert C, Moore AT, Moosajee M. Clinical utility gene card for: non-syndromic microphthalmia including next-generation sequencing-based approaches. Eur J Hum Genet. 2017; 25, https://doi.org/10.1038/ejhg.2016.201.

2. Verma AS, FitzPatrick DR. Anophthalmia and microphthalmia. Orphanet J Rare Dis. 2007;2:47, https://doi.org/10.1186/17501172-2-47

3. Schneider A, Bardakjian T, Reis LM, Tyler RC, Semina EV. Novel SOX2 mutations and genotype-phenotype correlation in anophthalmia and microphthalmia. Am J Med Genet A. 2009;149A:2706-15. https://doi.org/10.1002/ajmg.a.33098

4. Slavotinek A. Genetics of anophthalmia and microphthalmia. Part 2: syndromes associated with anophthalmia-microphthalmia. Hum Genet. 2018; 1-16, https://doi.org/10.1007/s00439-0181949-1.

5. Slavotinek AM. Eye development genes and known syndromes. Mol Genet Metab. 2011;104:448-56. https://doi.org/10.1016/j. ymgme.2011.09.029

6. Kallen B, Robert E, Harris J. The descriptive epidemiology of anophthalmia and microphthalmia. Int $\mathrm{J}$ Epidemiol. 1996;25:1009-16. https://doi.org/10.1093/ije/25.5.1009

7. Forrester MB, Merz RD. Descriptive epidemiology of anophthalmia and microphthalmia, Hawaii, 1986-2001. Birth Defects Res Part A Clin Mol Teratol. 2006;76:187-92. https://doi.org/10. 1002/bdra.20237

8. Shah SP, Taylor AE, Sowden JC, Ragge N, Russell-Eggitt I, Rahi JS, et al. Anophthalmos, microphthalmos, and coloboma in the United Kingdom: clinical features, results of investigations, and early management. Ophthalmology. 2012;119:362-8. https://doi. org/10.1016/j.ophtha.2011.07.039

9. Plaisancie J, Calvas P, Chassaing N. Genetic advances in microphthalmia. J Pediatr Genet. 2016;5:184-8. https://doi.org/10.1055/ s-0036-1592350

10. Williamson KA, FitzPatrick DR. The genetic architecture of microphthalmia, anophthalmia and coloboma. Eur J Med Genet. 2014;57:369-80. https://doi.org/10.1016/j.ejmg.2014.05.002

11. Chaitankar V, Karakülah G, Ratnapriya R, Giuste FO, Brooks MJ, Swaroop A. Next generation sequencing technology and genomewide data analysis: perspectives for retinal research. Prog Retin Eye Res. 2016;55:1-31. https://doi.org/10.1016/j.preteyeres.2016. 06.001

12. Riera M, Wert A, Nieto I, Pomares E. Panel-Based Whole Exome Sequencing Identifies Novel Mutations in Microphthalmia and Anophthalmia Patients Showing Complex Mendelian Inheritance Patterns. Mol Genet Genom Med. 2017;5:709-19. https://doi.org/ 10.1002/mgg3.329

13. Srour M, Caron V, Pearson T, Nielsen SB, Lévesque S, Delrue MA, et al. Gain-of-function mutations in RARB cause intellectual disability with progressive motor impairment. Hum Mutat. 2016;37:786-93. https://doi.org/10.1002/humu.23004

14. Srour M, Chitayat D, Caron V, Chassaing N, Bitoun P, Patry L, et al. Recessive and dominant mutations in retinoic acid receptor beta in cases with microphthalmia and diaphragmatic hernia. Am J Hum Genet. 2013;93:765-72. https://doi.org/10.1016/j.ajhg.2013. 08.014

15. Gerth-Kahlert C, Williamson K, Ansari M, Rainger JK, Hingst V, Zimmermann $\mathrm{T}$, et al. Clinical and mutation analysis of 51 probands with anophthalmia and/or severe microphthalmia from a single center. Mol Genet Genom Med. 2013;1:15-31. https://doi. org/10.1002/mgg3.2

16. Gonzalez-Rodriguez J, Pelcastre EL, Tovilla-Canales JL, GarciaOrtiz JE, Amato-Almanza M, Villanueva-Mendoza C, et al. Mutational screening of CHX10, GDF6, OTX2, RAX and SOX2 genes in 50 unrelated microphthalmia-anophthalmia-coloboma (MAC) spectrum cases. Br J Ophthalmol. 2010;94:1100-4. https://doi.org/10.1136/bjo.2009.173500

17. Clementi M, Turolla L, Mammi I, Tenconi R. Clinical anophthalmia: an epidemiological study in Northeast Italy based on 368,256 consecutive births. Teratology. 1992;46:551-3. https:// doi.org/10.1002/tera.1420460604

18. Shah SP, Taylor AE, Sowden JC, Ragge NK, Russell-Eggitt I, Rahi JS, et al. Anophthalmos, microphthalmos, and typical coloboma in the United Kingdom: a prospective study of incidence and risk. Investig Opthalmology Vis Sci. 2011;52:558-64. https:// doi.org/10.1167/iovs.10-5263 
19. Morrison D, FitzPatrick D, Hanson I, Williamson K, van Heyningen $\mathrm{V}$, Fleck B, et al. National study of microphthalmia, anophthalmia, and coloboma (MAC) in Scotland: investigation of genetic aetiology. J Med Genet. 2002;39:16-22. https://doi.org/ 10.1136/jmg.39.1.16

20. Chassaing N, Gilbert-Dussardier B, Nicot F, Fermeaux V, EnchaRazavi F, Fiorenza M, et al. Germinal mosaicism and familial recurrence of ASOX2 mutation with highly variable phenotypic expression extending from AEG syndrome to absence of ocular involvement. Am J Med Genet A. 2007;143A:289-91. https://doi. org/10.1002/ajmg.a.31524

21. Faivre L, Williamson KA, Faber V, Laurent N, Grimaldi M, Thauvin-Robinet C, et al. Recurrence of SOX2 anophthalmia syndrome with gonosomal mosaicism in a phenotypically normal mother. Am J Med Genet A. 2006;140A:636-9. https://doi.org/10. 1002/ajmg.a.31114

22. Kelberman D, Rizzoti K, Avilion A, Bitner-Glindzicz M, Cianfarani S, Collins J, et al. Mutations within Sox2/SOX2 are associated with abnormalities in the hypothalamo-pituitary-gonadal axis in mice and humans. J Clin Investig. 2006;116:2442-55. https://doi.org/10.1172/JCI28658

23. Ramirez-Botero AF, Pachajoa H. Syndromic microphthalmia-3 caused by a mutation on gene SOX2 in a colombian male patient. Congenit Anom (Kyoto). 2016;56:250-2. https://doi.org/10.1111/ cga. 12170

24. Schilter KF, Schneider A, Bardakjian T, Soucy J-F, Tyler RC, Reis LM, et al. OTX2 microphthalmia syndrome: four novel mutations and delineation of a phenotype. Clin Genet. 2011;79:158-68. https:// doi.org/10.1111/j.1399-0004.2010.01450.x

25. Ragge NK, Brown AG, Poloschek CM, Lorenz B, Henderson RA, Clarke MP, et al. Heterozygous mutations of OTX2 cause severe ocular malformations. Am J Hum Genet. 2005;76:1008-22. https://doi.org/10.1086/430721

26. Wyatt A, Bakrania P, Bunyan DJ, Osborne RJ, Crolla JA, Salt A, et al. Novel heterozygous OTX2 mutations and whole gene deletions in anophthalmia, microphthalmia and coloboma. Hum Mutat 2008;29:E278-E283. https://doi.org/10.1002/humu.20869

27. Tajima T, Ohtake A, Hoshino M, Amemiya S, Sasaki N, Ishizu K, et al. OTX2 loss of function mutation causes anophthalmia and combined pituitary hormone deficiency with a small anterior and ectopic posterior pituitary. J Clin Endocrinol Metab. 2009;94:314-9. https://doi.org/10.1210/jc.2008-1219

28. Tajima T, Ishizu K, Nakamura A. Molecular and clinical findings in patients with LHX4 and OTX2 mutations. Clin Pediatr Endocrinol. 2013;22:15-23. https://doi.org/10.1292/cpe.22.15

29. Voronina VA, Kozhemyakina EA, O'Kernick CM, Kahn ND, Wenger SL, Linberg JV, et al. Mutations in the human RAX homeobox gene in a patient with anophthalmia and sclerocornea. Hum Mol Genet. 2003;13:315-22. https://doi.org/10.1093/hmg/ ddh025

30. Chassaing N, Causse A, Vigouroux A, Delahaye A, Alessandri J$\mathrm{L}$, Boespflug-Tanguy $\mathrm{O}$, et al. Molecular findings and clinical data in a cohort of 150 patients with anophthalmia/microphthalmia. Clin Gene.t 2014;86:326-34. https://doi.org/10.1111/cge.12275

31. Plaisancié J, Ceroni F, Holt R, Zazo Seco C, Calvas P, Chassaing $\mathrm{N}$, et al. Genetics of anophthalmia and microphthalmia. Part 1: non-syndromic anophthalmia/microphthalmia. Hum Genet. 2019; 1-32, https://doi.org/10.1007/s00439-019-01977-y.

32. Chassaing N, Golzio C, Odent S, Lequeux L, Vigouroux A, Martinovic-Bouriel J, et al. Phenotypic spectrum of STRA6 mutations: from Matthew-Wood syndrome to non-lethal anophthalmia. Hum Mutat. 2009;30:E673-E681. https://doi.org/10. 1002/humu.21023.

33. Chassaing N, Ragge N, Kariminejad A, Buffet A, Ghaderi-Sohi S, Martinovic J, et al. Mutation analysis of the STRA6 gene in isolated and non-isolated anophthalmia/microphthalmia. Clin Genet. 2013;83:244-50. https://doi.org/10.1111/j.1399-0004. 2012.01904.x

34. Pasutto F, Sticht H, Hammersen G, Gillessen-Kaesbach G, FitzPatrick DR, Nürnberg G, et al. Mutations in STRA6 cause a broad spectrum of malformations including anophthalmia, congenital heart defects, diaphragmatic hernia, alveolar capillary dysplasia, lung hypoplasia, and mental retardation. Am J Hum Genet. 2007;80:550-60. https://doi.org/10.1086/512203

35. Slavotinek AM, Garcia ST, Chandratillake G, Bardakjian T, Ullah $\mathrm{E}, \mathrm{Wu} \mathrm{D}$, et al. Exome sequencing in 32 patients with anophthalmia/microphthalmia and developmental eye defects. Clin Genet. 2015;88:468-73. https://doi.org/10.1111/cge.12543

36. Abouzeid H, Favez T, Schmid A, Agosti C, Youssef M, Marzouk I, et al. Mutations in ALDH1A3 represent a frequent cause of microphthalmia/anophthalmia in consanguineous families. Hum Mutat. 2014;35:949-53. https://doi.org/10.1002/humu.22580

37. Fares-Taie L, Gerber S, Chassaing N, Clayton-Smith J, Hanein S, Silva E, et al. ALDH1A3 mutations cause recessive anophthalmia and microphthalmia. Am J Hum Genet. 2013;92:265-70. https:// doi.org/10.1016/j.ajhg.2012.12.003

38. Plaisancié J, Brémond-Gignac D, Demeer B, Gaston V, Verloes A, Fares-Taie L, et al. Incomplete penetrance of biallelic ALDH1A3 mutations. Eur J Med Genet. 2016;59:215-8. https:// doi.org/10.1016/j.ejmg.2016.02.004

39. Matthijs G, Souche E, Alders M, Corveleyn A, Eck S, Feenstra I, et al. Guidelines for diagnostic next-generation sequencing. Eur J Hum Genet. 2016;24:2-5. https://doi.org/10.1038/ejhg.2015.226

40. Shaw GM, Carmichael SL, Yang W, Harris JA, Finnell RH, Lammer EJ. Epidemiologic characteristics of anophthalmia and bilateral microphthalmia among 2.5 million births in California, 1989-97. Am J Med Genet A. 2005;137A:36-40. https://doi.org/ 10.1002/ajmg.a.30840

41. Källén B, Tornqvist K. The epidemiology of anophthalmia and microphthalmia in Sweden. Eur J Epidemiol. 2005;20:345-50.

42. Bermejo E, Martínez-Frías ML. Congenital eye malformations: clinical-epidemiological analysis of 1,124,654 consecutive births in Spain. Am J Med Genet. 1998;75:497-504.

43. Chambers TM, Agopian AJ, Lewis RA, Langlois PH, Danysh HE, Weber KA, et al. Epidemiology of anophthalmia and microphthalmia: prevalence and patterns in Texas, 1999-2009. Am J Med Genet A. 2018;176:1810-8. https://doi.org/10.1002/a jmg.a.40352

44. Crider KS, Cleves MA, Reefhuis J, Berry RJ, Hobbs CA, Hu DJ. Antibacterial medication use during pregnancy and risk of birth defects. Arch Pediatr Adolesc Med. 2009;163:978-85. https://doi. org/10.1001/archpediatrics.2009.188

45. Busby A, Dolk H, Armstrong B. Eye anomalies: seasonal variation and maternal viral infections. Epidemiology. 2005; 16:317-22.

46. Givens KT, Lee DA, Jones T, Ilstrup DM. Congenital rubella syndrome: ophthalmic manifestations and associated systemic disorders. Br J Ophthalmol. 1993;77:358-63. https://doi.org/10. 1136/bjo.77.6.358

47. Frenkel LD, Keys MP, Hefteren SJ, Roia-Pleszczynski M, Bellanti JA. Unusual eye abnormalities associated with congenital cytomegalovirus infection. Pediatrics. 1980;66:763-6.

48. Araujo E, Kawanami TE, Nardozza LMM, Milani HJF, Oliveira PS, Moron AF. Prenatal diagnosis of bilateral anophthalmia by 3D "Reverse Face" view ultrasound and magnetic resonance imaging. Taiwan J Obstet Gynecol. 2012;51:616-9. https://doi.org/10. 1016/j.tjog.2012.09.018

49. Chen C-P, Wang K-G, Huang J-K, Chang T-Y, Lin Y-H, Chin DTH, et al. Prenatal diagnosis of otocephaly with microphthalmia/ anophthalmia using ultrasound and magnetic resonance imaging. 
Ultrasound Obstet Gynecol. 2003;22:214-5. https://doi.org/10. 1002/uog. 135

50. Mashiach R, Vardimon D, Kaplan B, Shalev J, Meizner I. Early sonographic detection of recurrent fetal eye anomalies. Ultrasound Obstet Gynecol. 2004;24:640-3. https://doi.org/10.1002/uog.1748

51. Guichet A, Triau S, Lépinard C, Esculapavit C, Biquard F, Descamps $\mathrm{P}$, et al. Prenatal diagnosis of primary anophthalmia with a $3 q 27$ interstitial deletion involving SOX2. Prenat Diagn. 2004;24:828-32. https://doi.org/10.1002/pd.997

52. Ragge NK, Subak-Sharpe ID, Collin JRO. A practical guide to the management of anophthalmia and microphthalmia. Eye. 2007;21:1290-1300. https://doi.org/10.1038/sj.eye.6702858

53. Chitty LS, Lo YMD. Noninvasive prenatal screening for genetic diseases using massively parallel sequencing of maternal plasma DNA. Cold Spring Harb Perspect Med. 2015;5:a023085 https:// doi.org/10.1101/cshperspect.a023085

54. Lench N, Barrett A, Fielding S, McKay F, Hill M, Jenkins L, et al. The clinical implementation of non-invasive prenatal diagnosis for single-gene disorders: challenges and progress made. Prenat Diagn. 2013;33:555-62. https://doi.org/10.1002/pd.4124

55. Chitty LS, Bianchi DW. noninvasive prenatal testing: the paradigm is shifting rapidly. Prenat Diagn. 2013;33:511-3. https://doi. org/10.1002/pd.4136

56. Hill M, Karunaratna M, Lewis C, Forya F, Chitty L. Views and preferences for the implementation of non-invasive prenatal diagnosis for single gene disorders from health professionals in the United Kingdom. Am J Med Genet A. 2013;161:1612-8. https://doi.org/10.1002/ajmg.a.35972

57. New MI, Tong YK, Yuen T, Jiang P, Pina C, Chan KCA, et al. Noninvasive prenatal diagnosis of congenital adrenal hyperplasia using cell-free fetal DNA in maternal plasma. J Clin Endocrinol Metab. 2014;99:E1022-E1030. https://doi.org/10.1210/jc.2014-1118

58. Hill M, Finning K, Martin P, Hogg J, Meaney C, Norbury G, et al. Non-invasive prenatal determination of fetal sex: translating research into clinical practice. Clin Genet. 2011;80:68-75. https://doi.org/10.1111/j.1399-0004.2010.01533.x 